\title{
The Effects of Ethanol, Phenobarbital, and Baclofen on Ethanol Withdrawal in the Rhesus Monkey
}

\author{
Janet S. Tarika and Gail Winger \\ Departments of Psychology and Pharmacology, University of Michigan Medical School Ann Arbor, Michigan 48109, USA
}

\begin{abstract}
Physical dependence on ethanol was produced in four rhesus monkeys by IV ethanol administration every $8 \mathrm{~h}$. Ethanol was administered on each occasion until the eyeblink reflex was lost. Evidence of physical dependence development, in the form of tremoring $8 \mathrm{~h}$ after an infusion, appeared on day 8 of chronic administration. Abrupt cessation of ethanol administration following 16 days of chronic administration was accompanied by moderate to severe tremoring, retching, vomiting, and one or more convulsions. Peak withdrawal occurred between 12 and $32 \mathrm{~h}$ after abrupt discontinuation of ethanol administration, and decreased over a period of $64-204 \mathrm{~h}$. Ethanol dependence was then reinstated. Once every 3-4 days, ethanol was withheld for $16 \mathrm{~h}$. Withdrawal signs were scored for the first $12 \mathrm{~h}$ of this period, and then a test dose of ethanol, phenobarbital, or baclofen was administered. Withdrawal or intoxication signs were scored over the next $4 \mathrm{~h}$, at which time ethanol administration was resumed. Both ethanol and phenobarbital suppressed ethanol withdrawal signs in a dose-related manner, and produced dose-related intoxication. Baclofen was largely ineffective in reducing withdrawal-induced tremors, although it was capable of producing sedation of a different type than that produced by phenobarbital and ethanol.
\end{abstract}

Key words: Ethanol physical dependence Phenobarbital - Baclofen - Rhesus monkey

The production of physical dependence on ethanol in animals has proven useful in testing the effects of a variety of drugs on ethanol withdrawal signs. Several investigators have used ethanol-dependent animals to study drugs which are used clinically for the treatment

Offprint requests to: Gail Winger, Department of Pharmacology, M6322 Medical Science Building I, University of Michigan, Ann Arbor, MI 48109, USA of ethanol withdrawal (Essig et al. 1969; Goldstein 1972; Sprague and Craigmill 1976). Others have tested drugs that are known to interfere with certain neurotransmitters in the brain (Goldstein 1973, 1979; Cooper et al. 1979). Still others have searched for drugs that can specifically suppress withdrawal signs without producing generalized CNS depression or untoward side effects (Majchrowicz 1976; Noble et al. 1976). Although the data provided by these studies have been uniformly interesting and useful, there were some disadvantages in each. In most cases, rats or mice were experimental subjects, and the withdrawal sign scored was usually convulsions produced by handling or by sound, a sign with no clear counterpart in humans. Also, quantitative evaluation of the direct effect of the treatment drug on behavior has rarely been made, so that it is difficult to determine the amount of sedation that accompanies the observed drug effect on ethanol withdrawal signs.

In an attempt to overcome these disadvantages, we used rhesus monkeys as subjects in an experiment designed to evaluate the effect of three drugs on ethanol withdrawal. Ethanol dependence in monkeys has been produced by several investigators (Ellis and Pick 1970; Pieper et al. 1972; Pieper and Skeen 1972) and withdrawal has been shown to resemble closely the early phases of withdrawal in humans. In this study we measured tremor as our indicator of withdrawal, a measure with a direct counterpart in humans. In addition, we also recorded, in a quantitative manner, the sedation produced by the test drugs. This indication of the severity of drug-induced impairment which may accompany attenuation of withdrawal would be helpful in selecting an agent which might relieve withdrawal with the least amount of incapacitation.

The technique used was a modification of one used in similar studies of narcotic dependence (e.g., Himmelsbach and Andrews 1943). Physical dependence was produced by chronic drug administration; deprivation-induced withdrawal was interrupted at 
certain points by administration of a test drug. The preceding hours of withdrawal were used to determine the current dependent state, and the effect of the test drug on this state could be evaluated.

Three drugs were assessed as to their efficacy in suppressing the ethanol-withdrawal syndrome. The drugs were ethanol, phenobarbital, and baclofen. Ethanol and phenobarbital are known to reverse ethanol withdrawal in man and in many animal models of ethanol dependence. They were used to test the efficacy of this test design, and its comparability to other tests of drug effects on ethanol withdrawal. Baclofen [beta-(4-chlorophenyl)-gamma-aminobutyric acid] is a derivative of the putative neurotransmitter gamma-aminobutyric acid. Its structural similarity to GABA originally suggested that its actions might be related to activation of the GABA receptor. Although electrophysiologic and biochemical evidence have indicated that by and large, baclofen does not act directly on the GABA receptor (Naik et al. 1976), recent behavioral data indicate that it may have a weak GABA agonist effect, at least in some parts of the brain (Waddington and Cross 1979). The current interest in the possibility that alterations in the GABAergic system may produce marked changes in ethanol withdrawal (Goldstein 1973, 1979; Cooper 1979; Noble et al. 1976) increased our interest in investigating baclofen.

Baclofen was interesting also because it is useful clinically in treatment of spasticity and spasms (Pedersen et al. 1970; Hudgson and Weightman 1971; Brogden et al. 1974). Spasticity is one of the signs of ethanol withdrawal that has been observed in monkeys (Ellis and Pick 1970) Furthermore, baclofen has been reported to reduce the signs of morphine withdrawal in mice (Robson et al. 1977) although it has no known naloxone-reversible narcotic effects. The possibility that baclofen might be able to reduce 'withdrawal' in general was an interesting one.

\section{Materials and Methods}

Subjects. Four male rhesus monkeys (Macaca mulatta) weighing 4$5 \mathrm{~kg}$ served in all experiments. Each animal was surgically implanted with a chronic indwelling jugular catheter exiting at a midscapular site and passing through a harness and restraining arm to the exterior of the cage (Deneau et al. 1969). The monkeys were housed individually in cages $94 \times 94 \times 94 \mathrm{~cm}$. They were allowed free access to Purina Monkey Chow and water and were given assorted fruits and grains daily. During chronic ethanol administration, food intake decreased and diet was occasionally supplemented with $50-150 \mathrm{ml}$ Sustagen (4 tablespoons $/ 100 \mathrm{ml}$ water) via gastric intubation through the nasal passage. In addition, drinking water was occasionally supplemented with Tang (1 tsp/500 $\mathrm{ml})$.

Preliminary Experiments. Prior to catheterization and any ethanol administration, single observations of the effects of IM administration of various doses of baclofen and phenobarbital were made in order to select two doses of each drug for testing in the withdrawal experiments.

First, baclofen, in doses of $1.0,3.0$, and $10.0 \mathrm{mg} / \mathrm{kg}$ and saline were administered IM, one dose per monkey. Observations were subsequently made at $3,10,30,100$, and $300 \mathrm{~min}$. Three days later, $5.6 \mathrm{mg}$ baclofen $/ \mathrm{kg}$ body weight was given to the monkey who had previously received saline and observations were made at the time intervals listed above. Then, phenobarbital, in doses of 10,30 , and $56 \mathrm{mg} / \mathrm{kg}$, and saline were administered IM, again, one dose per monkey, and the animals were monitored as above.

Ethanol Administration and Withdrawal. Animals were made physically dependent on ethanol by administration of $27.5 \%(\mathrm{w} / \mathrm{v})$ ethanol every $8 \mathrm{~h}: 8$ a.m., 4 p.m., and 12 midnight. The ethanol was infused through the IV catheters using Sage Model 249-2 pumps. Infusion speed varied slightly according to the resistance of an individual animal's catheter, but averaged approximately $1.0 \mathrm{ml} / \mathrm{min}$. Each animal received enough ethanol to produce loss of the eyeblink reflex when the eyelid was touched. Observations were made both immediately prior to and $5 \mathrm{~min}$ following each ethanol administration. During this initial phase, ethanol was given three times daily for 16 days (period 1).

Withdrawal consisted of the period of time from the last dose of ethanol until all signs of withdrawal disappeared. Observations began $8 \mathrm{~h}$ after the last dose of ethanol and were made at $0,10,30$, 100 , and $300 \mathrm{~min}$ every $8 \mathrm{~h}$ until withdrawal began to subside. Thereafter, obervations were made at 8 - $h$ intervals, and later at $24-\mathrm{h}$ intervals until all withdrawal signs disappeared.

After withdrawal was complete in all animals, 7 days elapsed before ethanol administration was resumed.

The Effects of Baclofen and Phenobarbital on Ethanol Withdrawal. Ethanol was administered chronically (period 2) according to the procedure described above, with the addition that, following the first administration, a limit of $3 \mathrm{~g} / \mathrm{kg}$ was placed on each ethanol injection. On day 8 of period 2, the scheduled 8 a.m. dose of ethanol was omited. Starting at that time, $8 \mathrm{~h}$ after the last dose of ethanol, the animals were observed for withdrawal signs at $0,10,30,100$, and $210-240 \mathrm{~min}$. Baclofen or phenobarbital was given immediately following the last observation (i.e., $12 \mathrm{~h}$ after the last ethanol injection) and observations of the monkeys were made at 10,30, and $100 \mathrm{~min}$ following drug administration. The doses of phenobarbital used were 10.0 and $30.0 \mathrm{mg} / \mathrm{kg}$ and the doses of baclofen were 30 and $5.6 \mathrm{mg} / \mathrm{kg}$; volume was $0.2 \mathrm{ml} / \mathrm{kg}$. Each monkey received both doses of both drugs and saline. Order of administration was determined by a modified Latin square design. At 4 p.m., $16 \mathrm{~h}$ after the last dose of ethanol, ethanol administration was resumed according to schedule. This sequence was repeated every $2-3$ days.

After the 17th day of chronic ethanol administration, the monkeys appeared quite debilitated, and it was decided to discontinue ethanol administration temporarily. The animals went through complete withdrawal and were observed according to the procedure described previously. After withdrawal was complete, 12 days elapsed, then chronic administration of ethanol was begun again (period 3). On day 11 of this period, the 8 a.m. ethanol dose was omitted, and following $240 \mathrm{~min}$ of withdrawal, a test dose of baclofen, phenobarbital, or saline administered. After this, ethanol administration was resumed according to schedule, as baselines for the evaluation of the effects of ethanol on ethanol withdrawal.

The Effects of Ethanol on Ethanol Withdrawal. On day 14 of period 3, the first test dose of ethanol was administered IV through the same pump system that administered the chronic ethanol. On each test day, after the omitted ethanol infusion and after ethanol injection, observations were made at 0,60 , and $210-240 \mathrm{~min}$. Three doses of ethanol were tested: $0.3,1.0$, and $1.8 \mathrm{~g} / \mathrm{kg}$.

Observations. In all experiments, a grading sheet was used to assess and record the individual animals' behavior. The sheet included behaviors observed with some frequency following administration of 
baciofen, phenobarbital, ethanol, and ethanol withdrawal. Several of the items were recorded simply as present or absent : fasciculation, piloerection, salivation, eating, retching, vomiting. Two items were recorded by the direction of change: apprehension and aggression and three items were graded on a four-point scale: muscle weakness, ataxia, and tremor. Additional observations and comments were noted at the bottom of each sheet.

Muscle weakness was scored in the following way: $0=$ none; 1 $=$ limp wrist or droopy head, or slight difficulty standing; $2=$ definite difficulty standing or holding onto side of cage or sitting with head between knees; $3=$ sitting in cage but requiring support (harness, side of cage) to keep from falling over; $4=$ lying in cage, unable to sit.

The scoring system used for ataxia was the following: $0=$ none; $1=$ slightly staggered walk or slow reaction time; $2=$ definite staggered walk, lack of coordination or slow reaction time; $3=$ cannot keep balance when standing; $4=$ lying in cage unable to sit or stand. Following a high dose of test drug, it was occasionally difficult to distinguish severe ataxia from severe muscle weakness; in such cases, animals were given scores of 4 for both.

Tremors were rated according to the following scale: $0=$ none; $1=$ fine tremor of hand or legs with volitional movement (standing, grasping, grooming) $2=$ resting tremor (head, hand), gross tremoring with movement; 3 = hand tremoring too much to grasp or hold food, barely able to walk due to leg shaking; $4=$ spontaneous episodes of violent, gross shaking, near convulsion, unable to move without whole body shaking uncontrollably.

All observations following test drugs, including ethanol, were made by two observers. In the case of administration of baclofen, and phenobarbital, both observers were blind as to the dose and the drug administered. In the case of the ethanol administration, since it was given by itself later in the protocol and was given by a different route, both observers were aware that ethanol was being administered. However, the dose administered was not known, and it was not known which animal received saline. Daily observations of the monkeys before and after each ethanol infusion were also made by two observers at $8 \mathrm{a} . \mathrm{m}$. and 4 p.m. A single observer recorded the information at midnight.

Blood Ethanol. On the last day of chronic ethanol periods 1 and 2, blood samples were drawn from each monkey and analyzed for ethanol content. Samples were taken at three times : immediately after the termination of the ethanol infusion, i.e., when the monkey was unconscious; $3 \mathrm{~h}$ after the infusion; and just before the next infusion, $8 \mathrm{~h}$ after the previous ethanol administration. Blood was drawn from the saphenous vein of three of the monkeys, and from the catheter of the fourth monkey.

Samples were analyzed for ethanol content using a gas chromatograph with isopropyl ethanol as the internal standard.

Drugs. Baclofen was first dissolved in $0.5 \mathrm{ml}$ of $1 \mathrm{~N} \mathrm{NaOH}$. Two milliliters of saline were added and the solution was titrated to $\mathrm{pH}$ $=9$ with $1 \mathrm{~N} \mathrm{HCl}$. Phenobarbital was dissolved in distilled water. Both drugs were administered intramuscularly at $0.2 \mathrm{ml} / \mathrm{kg}$, according to each individual's weight.

Ethanol, in all cases, was a $27.5 \%(\mathrm{w} / \mathrm{v})$ solution of $95 \%$ ethanol in saline and was administered IV.

\section{Results}

Preliminary Experiments. Baclofen doses of 1.0 and $3.0 \mathrm{mg} / \mathrm{kg}$ had no observable effects; 5.6 and $10.0 \mathrm{mg} / \mathrm{kg}$ baclofen produced increases in muscle weakness scores and the animals appeared to be sedated. Written comments about these animals included: "dozes off if left alone; falls over while crouching; cannot lock straight ahead for a long time - eyes droop; holds onto side of cage; has 'blind' look." The two doses, 5.6 and $10.0 \mathrm{mg} / \mathrm{kg}$ were equally effective for the first $30 \mathrm{~min}$; thereafter, $10.0 \mathrm{mg} / \mathrm{kg}$ had a greater effect.

The phenobarbital dose of $10 \mathrm{mg} / \mathrm{kg}$ produced no observable effects. Following administration of 30 and $56 \mathrm{mg} / \mathrm{kg}$, animals showed increases in ataxia and decreases in aggression and apprehension. Animals were described as 'losing balance easily; falling over while sitting; staggering quite a bit when walking.' The two doses were equally effective for the first $30 \mathrm{~min}$; after that, $56 \mathrm{mg} / \mathrm{kg}$ had a greater effect.

For use in ethanol withdrawal experiments, two doses of each drug were chosen: the highest dose of each drug that had no observable effects, and the lowest dose that produced marked effects. The doses selected were $3.0 \mathrm{mg} / \mathrm{kg}$ and $5.6 \mathrm{mg} / \mathrm{kg}$ baclofen and $10 \mathrm{mg} / \mathrm{kg}$ and $30 \mathrm{mg} / \mathrm{kg}$ phenobarbital.

Ethanol Administration and Withdrawal. To produce physical dependence, ethanol was administered three times daily for 16 days (period 1). During an ethanol infusion, animals displayed typical signs of intoxication. They were initially ataxic and responded more slowly than usual to being approached by experimenters. As more ethanol was administered, occasional vomiting or retching occurred. The animals grew increasingly sedated to the point that they sat motionless with their eyes shut and seemed to go to sleep. Eventually they fell over in their cages and became comatose, failing to exhibit an eyeblink reflex.

The amount of ethanol required to produce loss of the blink reflex increased gradually over the entire period of administration. For the first week (days $1-$ 8), the average amount of ethanol necessary to produce a loss of eyeblink reflexes was $1.55 \pm 0.7 \mathrm{~g} / \mathrm{kg}$, and for the last 7 days (day $10-16$ ), it was $2.04 \pm 0.5 \mathrm{~g} / \mathrm{kg}$.

Figure 1, top panel, shows amounts of ataxia and tremor observed before each ethanol administration, $8 \mathrm{~h}$ after the previous dose of ethanol, in period 1. During the first 8 days, average pre-injection ataxia scores generally declined; by the ninth day, preinjection ataxia was negligible. Pre-injection tremoring began to appear on the eighth day of period 1 and tremor scores increased gradually for the remainder of the period.

Throughout the course of chronic administration, food intake was reduced. The animais ate no chow and only occasionally fruit or grain. Weight loss, measured from day 1 to day 16 , averaged $0.62 \pm 0.06 \mathrm{~kg}$ for the four monkeys during period 1 .

By $8 \mathrm{~h}$ after the last dose of ethanol, the average tremor score was 1.25. During the next $4 \mathrm{~h}$, tremor scores increased rapidly and by the 12 th hour of 


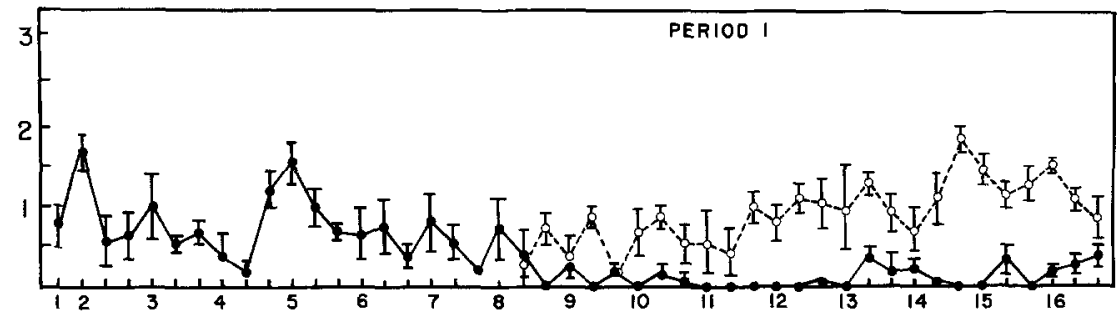

O TREMOR

- atAXIA

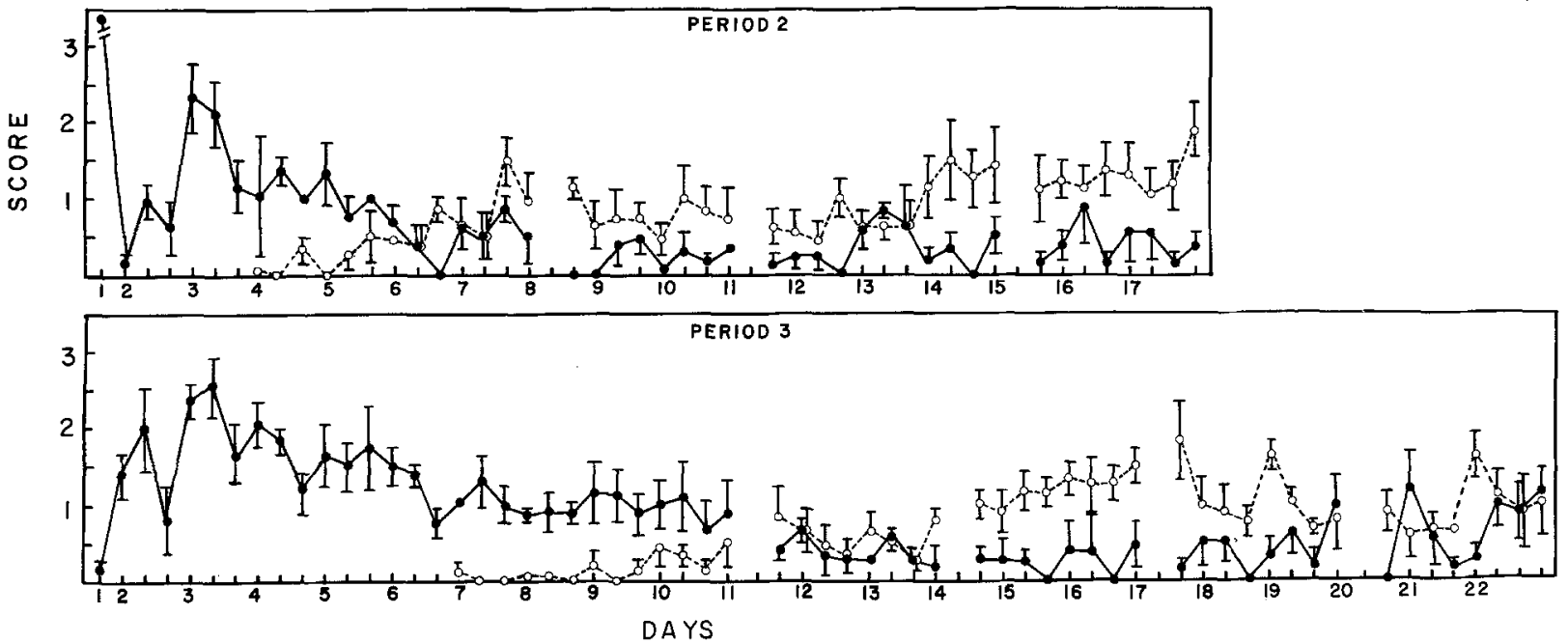

Fig. 1. Effects of ethanol $8 \mathrm{~h}$ after administration for three chronic administration periods. The ordinate represents average ataxia $(--)$ and tremor $\left(-O^{-}\right)$scores. The abscissa shows time of observation in days. Ethanol was administered three times daily, at 8 a.m., 4 p.m., and 12 midnight; thus each point represents an observation made before each administration of ethanol, or $8 \mathrm{~h}$ after the previous dose. Top panel chronic administration period 1 ; middle panel chronic administration period $2 ;$ bottom panel chronic administration period 3 . Breaks in the graphs in the middle and bottom panels represent days when an ethanol administration was omited and test drugs were given. Tremor scores prior to the time they appear on the graphs were all 0 . Points represent means for four animals; brackets signify $\pm 1 \mathrm{SE}$

withdrawal, the average was 3.0. Convulsion, which were seen in three of the four animals, all occurred between 11 and $15 \mathrm{~h}$ after the last dose of ethanol. Withdrawal peaked, in general, at $12-24 \mathrm{~h}$ and tremor scores gradually declined for the remainder of the withdrawal period. Withdrawal signs had completely disappeared by $64 \mathrm{~h}$ in one animal, $84 \mathrm{~h}$ in another, and $204 \mathrm{~h}$ in the other two monkeys.

In three monkeys, episodes of $10-15 \mathrm{~s}$ of severe shaking (tremor score $=3-4$ ) were seen at $9.5-12 \mathrm{~h}$ after the last dose of ethanol. The shaking increased in frequency to the point that, by 13 and $15 \mathrm{~h}$ respectively, each animal was lying on the floor of his cage in a 'spread eagle' position, gripping the floor tightly with hands and feet. Tremoring became even more violent, and apparently uncontrollable, if the animal attempted to move. One of these monkeys had a single full-scale convulsion which appeared after several seconds of severe shaking. Another monkey had nine convulsions and was given $0.2 \mathrm{mg} / \mathrm{kg}$ diazepam IV. His tremor scores were reduced for $2.5 \mathrm{~h}$ and then increased again, but no further convulsions were observed.

The fourth monkey never showed the degree nor the frequency of the tremulousness and shaking episodes that the other three showed. Throughout withdrawal, this animal was able to sit quietly, for the most part, with his eyes closed, although alert and apprehensive in response to noise. If provoked, he became tremulous (tremor score $=2-3$ ). This monkey had one convulsion, $13 \mathrm{~h}$ after the last dose of ethanol.

Chronic Ethanol in Periods 2 and 3. On the first injection of the second period of chronic ethanol administration, an average of $4.9 \mathrm{~g} / \mathrm{kg}$ ethanol was required to produce loss of eyeblink. This caused such marked and longlasting intoxication that the second infusion was omitted. Thereafter, each infusion was limited to no more than $3 \mathrm{~g} / \mathrm{kg}$. The amount of ethanol given increased progressively over the second period from an initial level of $2.10 \pm 0.13 \mathrm{~g} / \mathrm{kg}$ for days $2-7$ to a maximum of $2.48 \pm 0.14 \mathrm{~g} / \mathrm{kg}$ for the final 3 days (days $15-17$ ). Figure 1, second panel, shows average ataxia and tremor scores taken during period $2,8 \mathrm{~h}$ after each dose of ethanol. Ataxia scores declined gradually over the first part of the period and remained low after day 8 . Tremors began to appear prior to ethanol administration on day 4 and tremor scores increased over the period. 
Fig. 2

Effects of baclofen on ethanol withdrawal. Top panel tremor scores; bottom panel muscle weakness scores. The ordinate shows average score and the abscissa shows time, in minutes, relative to baclofen administration. Baclofen administration occurred at time 0 , as indicated by the arrow, $12 \mathrm{~h}$ after the last dose of ethanol. Data points to the left of time 0 represent mean scores for all animals prior to receiving saline, $3.0 \mathrm{mg} / \mathrm{kg}$ baclofen, or $5.6 \mathrm{mg} / \mathrm{kg}$ baclofen $(N=12)$; data points to the right of time 0 represent means for four animals on a single dose $(N=4) . \square$ Saline; $3.0 \mathrm{mg} / \mathrm{kg}$ baclofen; $\Delta 5.6 \mathrm{mg} / \mathrm{kg}$ baclofen. Brackets represent $\pm 1 \mathrm{SE}$

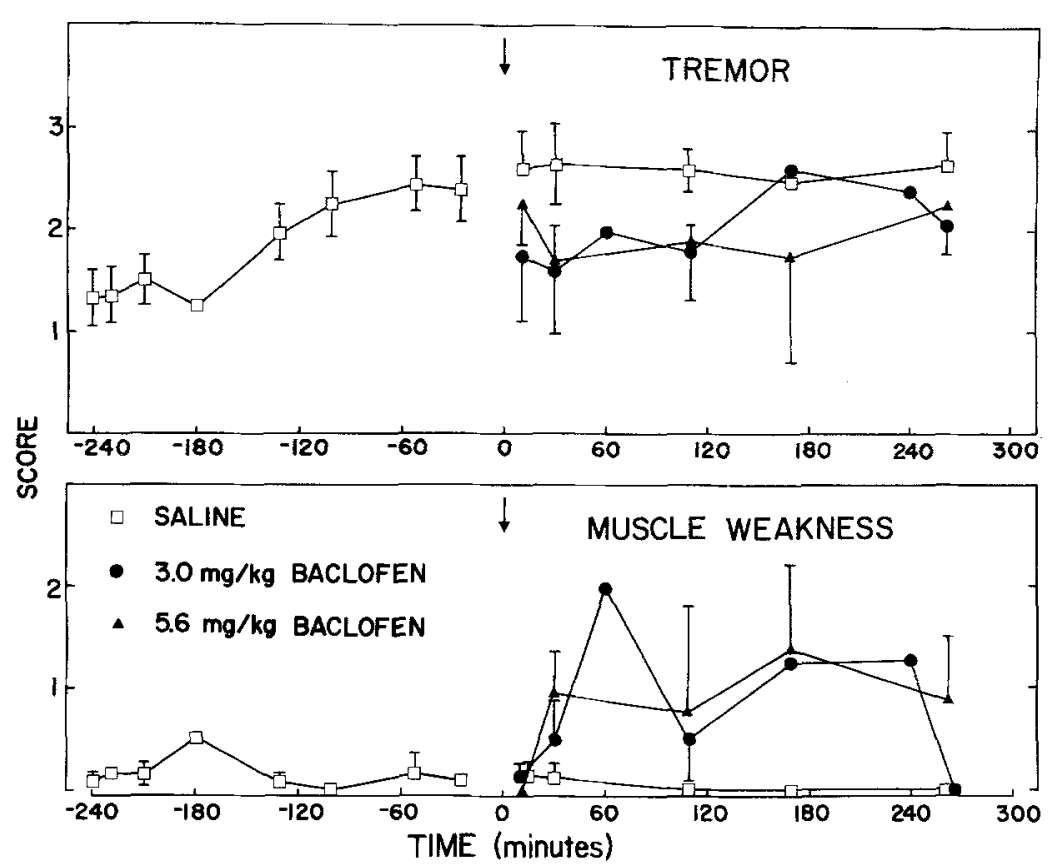

Four interruptions in ethanol administration occurred during period 2 , on days $8,11,15$, and 18 . These were the days on which doses of phenobarbital and baclofen were tested. On day 18 of period 2, when test day 4 occurred, ethanol administration was terminated and the animals went through extended ethanol withdrawal. After an 8-day withdrawal period, 12 days elapsed, then period 3 was begun. As with period 2, the average of amount of ethanol necessary to produce loss of the blink reflex increased gradually over the period. For days $2-10$, the average was $2.13 \pm 0.05 \mathrm{~g} / \mathrm{kg}$; for days $20-22$, it was $2.55 \pm 0.11 \mathrm{~g} / \mathrm{kg}$. Figure 1 , bottom panel, depicts average ataxia and tremor scores for period 3. Ataxia scores decreased over the first part of the period, and in period 2, and remained low after day 11 with slight increases at the end of the period. Tremors appeared on day 10 in all but one animal. Tremor scores increased over a 7 -day period (days $10-$ 18), then appeared to stabilize. In period 3, as well as in period 2 , the ataxia observed $8 \mathrm{~h}$ after each dose of ethanol failed to disappear altogether despite the fact that tremors began to develop. We were frequently able to observe ataxia and tremors in the same monkey at the same time.

Period 3 was interrupted five times. The first interruption, day 11, occurred when the final test of phenobarbitol or baclofen effects was conducted. The next four times, days $14,17,20$, and 22 , occurred when ethanol's effects on ethanol withdrawal were evaluated.

The Effects of Baclofen, Phenobarbital, and Ethanol on Ethanol Withdrawal. Figure 2 shows the effects of baclofen on ethanol withdrawal. Baclofen, at 3.0 and
$5.6 \mathrm{mg} / \mathrm{kg}$, produced only a slight reduction in tremor scores. The dose of $3.0 \mathrm{mg} / \mathrm{kg}$, which had no effect in these monkeys before ethanol administration and withdrawal, now caused increases in muscle weakness scores and sedation. The monkeys were observed to be: 'falling asleep sitting hunched over; barely holding himself up; drooping eyes.' With both doses of baclofen, several monkeys showed increases in aggressiveness. Four hours after administration $(15 \mathrm{~h}$ after the last dose of ethanol), $3.0 \mathrm{mg} / \mathrm{kg}$ baclofen failed to prevent convulsions in one monkey. No convulsions were seen following either $5.6 \mathrm{mg} / \mathrm{kg}$ baclofen or saline.

Figure 3 shows the effects of phenobarbital on ethanol withdrawal. Both doses of phenobarbital were successful in reducing tremor scores somewhat for up to $4 \mathrm{~h}$. The $10 \mathrm{mg} / \mathrm{kg}$ dose produced more tremor reduction than baclofen only at $30 \mathrm{~min}$ following the injection. The higher dose was more effective and had a longer duration of action than the lower dose. The dose of $10 \mathrm{mg} / \mathrm{kg}$ produced ataxia in one animal and some signs of sedation in all animals. The dose of $30 \mathrm{mg} / \mathrm{kg}$ produced moderate ataxia and sedation in all animals. Both doses failed in several cases to reduce the predrug increases in apprehension and aggression. No convulsions occurred following either dose of phenobarbital or saline.

In Figure 4, the effects of three doses of ethanol and saline on ethanol withdrawal are shown. The lowest dose of ethanol, $0.3 \mathrm{~g} / \mathrm{kg}$, was only slightly effective in reducing tremor scores. It also produced little or no ataxia and had no effect on increases in apprehension and aggression. Two animals had convulsions after receiving this dose, one after $90 \mathrm{~min}(13 \mathrm{~h}$ after ethanol 


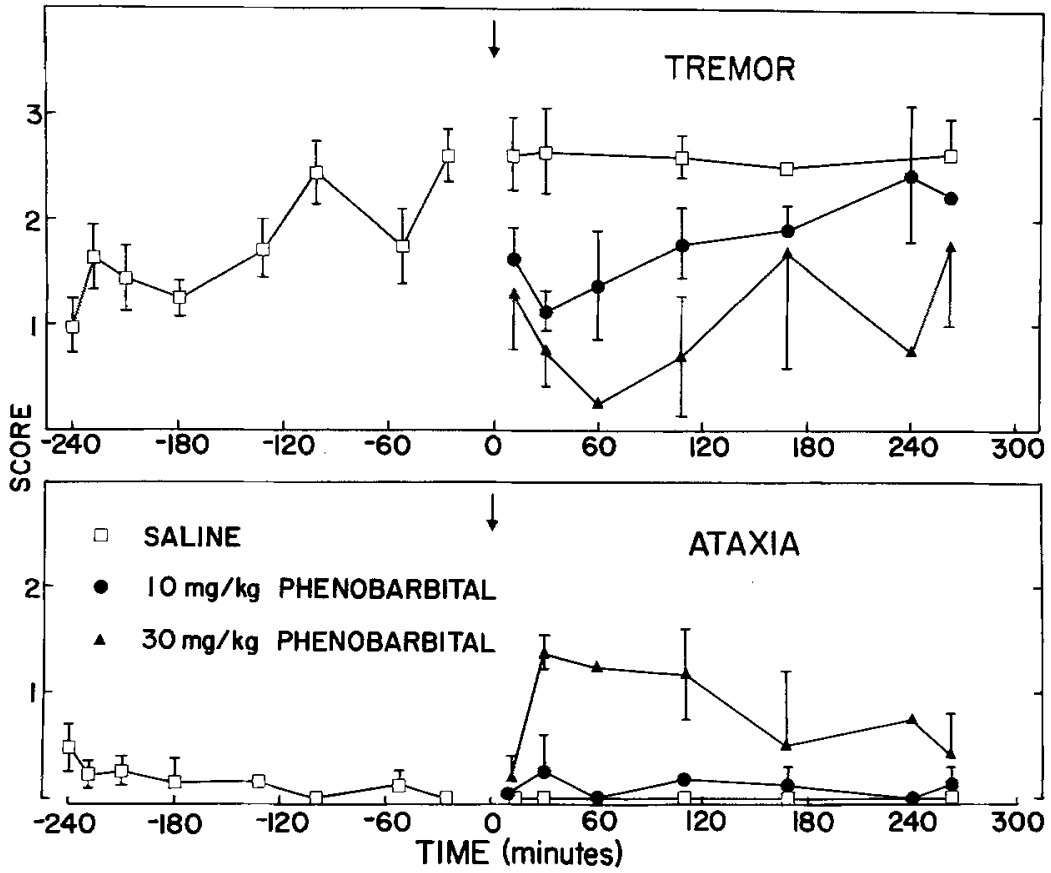

Fig. 3

The effects of phenobarbital on ethanol withdrawal. Top panel tremor scores; bottom panel ataxia scores. See the caption of Figure 2 for further details. $\square$ Saline; $10 \mathrm{mg} / \mathrm{kg}$ phenobarbital; $430 \mathrm{mg} / \mathrm{kg}$ phenobarbital. Brackets signify $\pm 1 \mathrm{SE}$

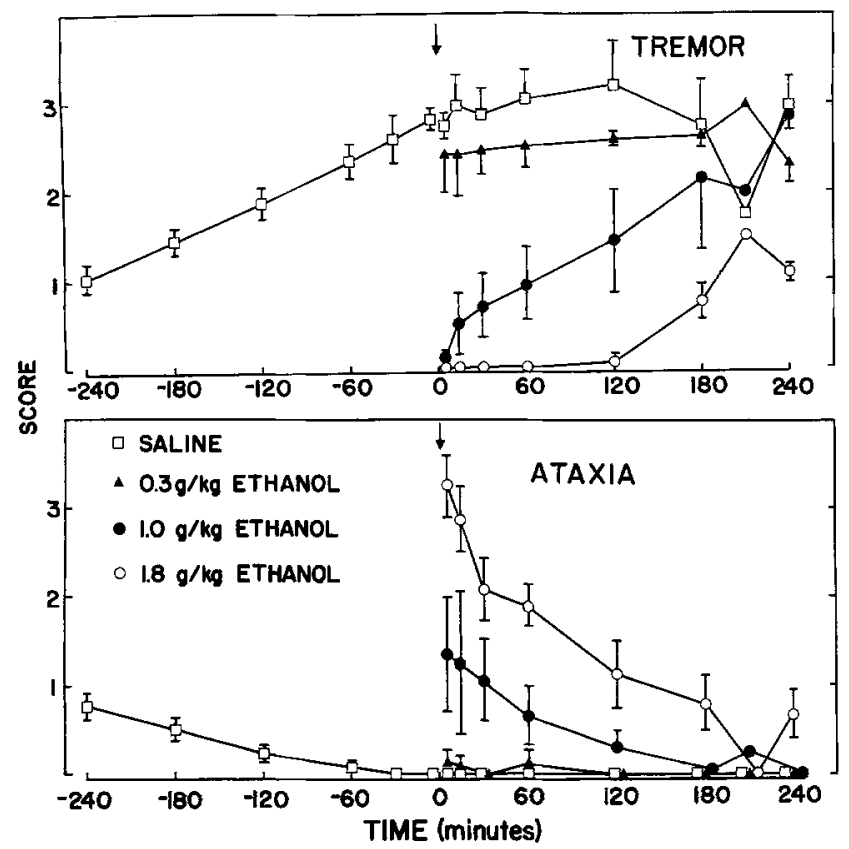

Fig. 4. The effects of ethanol on ethanol withdrawal. Top panel tremor scores; bottom panel ataxia scores. See the caption of Figure 2 for further details. $\square$ Saline; $\Delta 0.3 \mathrm{~g} / \mathrm{kg}$ ethanol; $1.0 \mathrm{~g} / \mathrm{kg}$ ethanol; $01.8 \mathrm{~g} / \mathrm{kg}$ ethanol. Brackets signify $\pm 1 \mathrm{SE}$

withdrawal) and one after $225 \mathrm{~min}(15 \mathrm{~h}$ after ethanol withdrawal). In contrast, both $1.0 \mathrm{~g} / \mathrm{kg}$ and $1.8 \mathrm{~g} / \mathrm{kg}$ ethanol immediately suppressed tremors completely. After $10 \mathrm{~min}, 1.8 \mathrm{~g} / \mathrm{kg}$ was more effective than $1.0 \mathrm{~g} / \mathrm{kg}$ in suppressing tremors, although with the latter, tremor scores remained below predrug levels for at least $3 \mathrm{~h}$. Both the 1.0 and $1.8 \mathrm{~g} / \mathrm{kg}$ doses of ethanol produced ataxia and sedation, the higher dose having a severe effect for several hours. One monkey had convulsions $180 \mathrm{~min}$ after receiving $1.0 \mathrm{~g} / \mathrm{kg}$ ethanol $(14.5 \mathrm{~h}$ after ethanol withdrawal) where none was seen after $1.8 \mathrm{~g} / \mathrm{kg}$. The inter-observer correlations for observations of tremor was 0.91 , and for observations of direct effects (ataxia and muscle weakness) was 0.84 .

Blood Ethanol. Blood samples drawn from each monkey on the last day of ethanol administration of periods 1 and 2 revealed a mean blood alcohol level of $227.5 \pm 21.4 \mathrm{mg} / 100 \mathrm{ml}$ of blood. The average blood ethanol level for the monkey whose sample was drawn from the catheter was slightly higher than the average levels in blood taken from the saphenous vein $(259 \mathrm{mg} / 100 \mathrm{ml}$ vs. $217 \mathrm{mg} / 100 \mathrm{ml})$. This may have been due to residual ethanol in the catheter. The monkeys were unconscious at the time this sample was drawn, due to the immediately prior administration of ethanol. The average blood ethanol level was $156.4 \pm$ $21.6 \mathrm{mg} / 100 \mathrm{ml}$ of blood at $3 \mathrm{~h}$ after the infusion and $103.1 \pm 15.3 \mathrm{mg} / 100 \mathrm{ml}$ of blood at $8 \mathrm{~h}$ after the infusion. Average rate of ethanol disappearance was $17.9 \mathrm{mg} / 100 \mathrm{ml} / \mathrm{h}$. Thus, if these data are typical, there was ethanol remaining in the blood $8 \mathrm{~h}$ after the final infusion. The observations of ataxia, $8 \mathrm{~h}$ after injections early in each period, give behavioral credence to this finding. There was no differences in either peak blood ethanol level or ethanol disappearance rate from the end of period 1 to the end of period 2. 


\section{Discussion}

Withdrawal from ethanol in primates has been described in some detail by Deneau et al. (1969), Ellis and Pick (1970), Pieper and Skeen (1972), Pieper et al. (1972), and Winger and Woods (1973). For the most part, the data presented here have substantiated these reports and parallel the descriptions of ethanol withdrawal in humans (Isbell et al., 1955; Victor and Adams 1953; Mendelson and La Dou 1964). Tremulousness, increased apprehension and aggression, anorexia, vomiting, and retching were the salient features of the initial phases of withdrawal. At the peak of withdrawal, severe preconvulsive behavior was seen in three monkeys and convulsions were observed in all four monkeys. Thus, with the exception of delirium tremens, the major aspects of ethanol withdrawal, as they have been described in humans, were evident in our animals, supporting the value of using primates in studies of ethanol dependence.

Previous investigators have found that drugs that are pharmacologically related to ethanol are effective in relieving the ethanol withdrawal syndrome. Ethanol itself is very effective in suppressing ethanol abstinence signs (Ellis and Pick 1970; Goldstein 1972; Blum et al. 1976; Sprague and Craigmill 1976); however, it is reported to be of limited use clinically because of its narrow margin of safety and short duration of action (Isabell et al. 1955; Golbert et al. 1967). Of the drugs tested in these studies, ethanol was the most effective in reversing withdrawal signs; however, it did so only at doses which produced moderate to severe ataxia, and even at the highest dose, it had a relatively short duration of action. Phenobarbital, which has a longer duration of action, has been reported by Goldstein (1972) to relieve ethanol abstinence signs in mice for long periods of time; it has also been used by Isbell et al. (1955) to treat humans in severe ethanol withdrawal. In the present experiments, phenobarbital successfully reduced the severity of withdrawal for the entire test period and produced moderate amounts of ataxia and sedation only at the higher dose. Baclofen, despite the fact that it produced a general sedation, was not as useful in suppressing ethanol withdrawal tremors. The slight amount of tremor suppression observed was accompanied by considerable muscle weakness and increased apprehension and aggression. It appears that the sedative effects of baclofen are unrelated to those of the barbiturates of ethanol.

Goldstein (1979) has reported that IP administered muscimol, a GABA receptor agonist, has no effect on ethanol withdrawal convulsions in mice. Cooper et al. (1979) found that muscimol, as well as GABA itself, when given IV were active in reducing sound-induced convulsions in ethanol withdrawn rats. Other
GABAergic compounds have also been shown to reduce withdrawal signs in rodents (Goldstein 1973). Our observations show that baclofen does not protect against withdrawal-induced tremoring in monkeys, indicating that baclofen, at least when given IM, may not have GABAergic effects centrally.

In the experiments reported here, ethanol dependence developed after only 7-16 days of chronic administration. This corroborates the findings of Ellis and Pick (1970) that only 10-18 days were necessary initially to produce physical dependence, and in subsequent cycles, as few as 5 days were required. It has been suggested that, in general, animals with previous histories of ethanol withdrawal require less exposure to ethanol to reproduce ethanol dependence (Branchey et al. 1971). Our results, however, did not necessarily bear this out. Signs of withdrawal, i.e., tremors, appeared after 8 days in the first period of chronic administration, and after 4 days in the second, but not until after 10 days in the third. This was remarkably uniform among animals in that, with the exception of one monkey in the third period, all animals showed first signs of tremoring within $48 \mathrm{~h}$ of one another. Goldstein (1974) has reported that if insufficient time is allowed between cycles of intoxication, recovery will be incomplete and ethanol dependence will carry over from one cycle into the next. Since less time elapsed between chronic administration periods 1 and 2 than between 2 and 3 , the most plausible explanation for our results is that there was an acumulation or carry over of physical dependence from period 1 to period 2 but not from period 2 to period 3 .

Our observations of the simultaneous occurrence of tremors and ataxia have not, to our knowledge, been reported previously, although it is well known that ethanol withdrawal can occur following a decline in ethanol blood levels, but while these blood levels are still substantial.

Several investigators have reported evidence of tolerance developing during chronic ethanol administration (Isbell et al. 1955; Mendelson and La Dou 1964; Ellis and Pick 1970; Falk et al. 1972; Pieper and Skeen 1972; Pieper et al. 1972). In agreement with these findings, our results demonstrated the development of tolerance in two different ways. First, within each period, the amount of ethanol given to the animals to produce loss of the eyeblink reflex gradually increased from beginning to end. Second, the ataxia observed $8 \mathrm{~h}$ after each dose of ethanol decreased over time within each period (Fig. 1). Kalant et al. (1971) have suggested that the appearance of withdrawal signs in the intervals between doses may mean the duration of the effect of each dose is diminishing. Thus, the appearance of tremors and the decreases in ataxia could have been indicative of decreases in the duration of action of each 
dose of ethanol, that is of development of metabolic tolerance. Decreases in pre-injection ataxia developed rapidly within the first several days of each chronic administration period, well before physical dependence was apparent, suggesting that this type of tolerance may be independent of physical dependence.

The experiments described here have demonstrated the successful use of a technique for repeated evaluation of the effects of drugs on the ethanol-withdrawal syndrome in primates. Physical dependence was produced in a relatively short amount of time and maintained for extended periods despite recurrent interruptions for testing the effects of drugs on withdrawal. In addition, repeated episodes of the withdrawal signs were successfully produced so that several doses of several drugs could be tested in the same subject during chronic administration. Observations of the direct effect of the administered drug, in addition to its effect on withdrawal-induced tremoring could be evaluated in this procedure. These observations would make possible the selection of a drug with maximal withdrawal reducing effects and minimal ataxia-producing effects. The major limitation on the duration of the dependent state was the animals' health, which deteriorated over the time of the experiment during chronic administration of ethanol. It would be particularly useful to devise a method for maintaining normal eating and drinking behavior while administering ethanol chronically to primates.

Acknowledgements. We thank Seymore Herling for his technical assistance and J. H. Woods for his direction and advice. This research was supported by USPHS grants AA 02544, DA 02230 and a gift from the Ciba-Geigy Corporation.

\section{References}

Blum K, Wallace JE, Schwerter HA, Eubanks JD (1976) Morphine suppression of ethanol withdrawal in mice. Experientia $32: 79-82$

Branchey M, Rauscher G, Kissin B (1971) Modifications in the response to alcohol following the establishment of physical dependence. Psychopharmacologia 22:314-322

Brogden RN, Speight TM, Avery GS (1974) Baclofen: A preliminary report of its pharmacological properties and therapeutic efficacy in spasticity. Drugs $8(1): 1-14$

Cooper BR, Viik K, Ferris RM, White HL (1979) Antagonism of the enhanced susceptibility to audiogenic seizures during alcohol withdrawal in the rat by $\gamma$-amino butyric acid (GABA) and "GABA-mimetic" agents. J Pharmacol Exp Ther 209:396-403

Deneau GA, Yanagita AT, Seevers MH (1969) Self-administration of psychoactive substances by the monkey: A measure of psychological dependence. Psychopharmacologia 16:30-48

Ellis FW, Pick JF (1970) Experimentally induced ethanol dependence in rhesus monkeys. J Pharmacol Exp Ther 175:88-93

Essig CF, Jones BE, Lam RC (1969) The effect of pentobarbital on alcohol withdrawal in dogs. Arch Neurol (Chicago) 20:554558
Falk JL, Samson HH, Winger G (1972) Behavioral maintenance of high blood ethanol and physical dependence in the rat. Science (Washington) 177:811-813

Golbert TM, Sanz CJ, Rose HD, Leitschuh TH (1967) Comparative evaluation of treatments of alcohol withdrawal syndromes. $\mathbf{J}$ Amer Med Assoc 201:99-102

Goldstein DB (1972) An animal model for testing effects of drugs on alcohol withdrawal reactions. J Pharmacol Exp Ther 183:1422

Goldstein DB (1973) An animal model for testing effects of drugs that modify neurotransmission. J Pharmacol Exp Ther 186:1-9

Goldstein DB (1974) Rates of onset and decay of alcohol physical dependence in mice. J Pharmacol Exp Ther 190:377-383

Goldstein DB (1979) Sodium bromide and sodium valproate: Effective suppressants of ethanol withdrawal reactions in mice. J Pharmacol Exp Ther 208:223-227

Himmelsbach CK, Andrews HL (1943) Studies on modification of the morphine abstinence syndrome by drugs. J Pharmacol Exp Ther 77:417-23

Hudgson P, Weightman D (1971) Baclofen in the treatment of spasticity. Br Med J 4:15-17

Isbell H, Fraser HF, Wikler A, Belleville RE, Eisenman AJ (1955) An experimental study of the etiology of "rum fits" and delirium tremens. Q J Stud Alcohol 16:1 - 33

Kalant H, LeBlanc AE, Gibbins RJ (1971) Tolerance to, and dependence on, some non-opiate psychotropic drugs. Pharmacol Rev 23:135-191

Majchrowicz E, Hunt WA, Piantadosi C (1976) Suppression by 1,3butanediol of the ethanol withdrawal syndrome in rats. Science (Washington) 194:1181-1182

Mendelson JH, La Dou J (1964) Experimentally induced chronic intoxication and withdrawal in alcoholics. Q I Stud Alcohol Suppl 2:14-39

Naik SR, Guidotti A, Costa E (1976) Central GABA receptor agonists: Comparison of muscimol and baclofen. Neuropharmacology 15 (8):479-484

Noble EP, Gillies R, Vigran R, Mandel P (1976) The modification of the ethanol withdrawal syndrome in rates by di-n-propylacetate. Psychopharmacologia 46:127-131

Pedersen E, Arlien-Soborg P, Grynderup V, Henriksen O (1970) GABA derivative in spasticity. Acta Neurol Scand 46:257-266

Pieper WA, Skeen MJ (1972) Induction of physical dependence on ethanol in rhesus monkeys using oral acceptance technique. Life Sci 11:989-997

Pieper WA, Skeen MJ, McClure HM, Bourne PG (1972) The chimpanzee as an animal model for investigating alcoholism. Science (Washington) 176:71-73

Robson RE, Saelens JK, Wilson D (1977) Suppression of morphine withdrawal symptoms by baclofen (BF) (Lioresal ${ }^{\circledR}$ ). Fed Proc 36:1025

Sprague GL, Craigmill AL (1976) Control of ethanol withdrawal symptoms in mice by phenytoin. Res Commun Chem Pathol Pharmacol 15:721-734

Victor M, Adams RD (1953) The effect of alcohol on the nervous system. Res Publ Assoc Res Nerv Ment Dis 32:526-273

Waddington JL, Cross AJ (1979) Baclofen and muscimol: Behavioral and neurochemical sequelae of unilateral intranigral administration and effects on ${ }^{3} \mathrm{H}-\mathrm{GABA}$ receptor binding. Arch Pharmacol 306:275-280

Winger GD, Woods JH (1973) The reinforcing properties of ethanol in the rhesus monkey. I. Initiation, maintenance and termination of intravenous ethanol-reinforced responding. Ann N Y Acad Sci $215: 162-175$

Received March 20, 1979; Final version June 5, 1980 